\title{
Burnout and Job Stress of Anaesthesiologists in The Tertiary-Class A Hospital Northwest China: A Questionnaire Survey
}

\section{Guang Yang}

Xi'an Honghui Hospital Affiliated to Xi'an Jiaotong University

\section{Xiaoli Fu}

Northwest Women's and Children's Hospital

\section{Miao He}

Xiangya Hospital Central South University

\section{Zhong Qing}

Xi'an Honghui Hospital Affiliated to Xi'an Jiaotong University

\section{Buhuai Dong}

Xi'an Honghui Hospital Affiliated to Xi'an Jiaotong University

Jiumin Ye ( $\nabla 15130556 @ q q . c o m)$

Xi'an Honghui Hospital Affiliated to Xi'an Jiaotong University

\section{Research Article}

Keywords: Anaesthesiologist, Burnout, Job Stress, Questionnaire survey

Posted Date: August 24th, 2021

DOI: https://doi.org/10.21203/rs.3.rs-620655/v1

License: (1) This work is licensed under a Creative Commons Attribution 4.0 International License. Read Full License 


\section{Abstract \\ Background}

Our purpose was to assess job stress and burnout among anaesthesiologists in The Tertiary-class A Hospital Northwest China.

\section{Objectives}

Analyzes the possible causes and adverse consequences of increased job stress and burnout of anaesthesiologists in this region and puts forward suggestions in combination with the current national policies.

\section{Study Design:}

Questionnaire survey.

\section{Setting:}

Data were collected in the Northwest China from February 2020 until April 2020.

\section{Methods}

We sent electronic questionnaires to all 1960-2017 practising anaesthesiologists of The Tertiary-class A Hospital Northwest China. Of those, 338 (67.6\%) were returned and could be used for analysis. Burnout and job stress were assessed by using modified Maslach Burnout Inventory-Human Services Survey and Chinese Perceived Stress Scale, respectively.

\section{Results}

First, as for emotional exhaustion, the situations of anaesthesiologists with different working years and workload are different with statistical significance $(P<0.05)$; Second, as for depersonalization, the situations of anaesthesiologists with different age, professional title, working years, physical health status and workload are different $(P<0.05)$; Third, as for personal accomplishment, the situations of anaesthesiologists with different physical health status are different $(P<0.05)$; Finally, The regression results showed that the longer the fatigue working years and the worse the physical health of anaesthesiologists in Northwest China, the more likely these two factors were to cause burnout $(P<0.05)$, as for job stress, there was a negative correlation between job stress and physical health status $(P<$ $0.05)$. 


\section{Conclusions}

Burnout and high job pressure are common among anaesthesiologists in The Tertiary-class A Hospital in Northwest China. We should focus on the allocation of labor intensity, pay attention to the physical and mental health of employees, establish targeted incentive mechanism, and improve the system of promotion and income rises for grassroots doctors. This may be not only conducive to the quality of medical care for patients, but also conducive to the development of anaesthesiology in China.

\section{Trial Registration:}

ChiCTR2000031316. Date registered: Mar 27, 2020.

\section{Introduction}

Burnout is a comprehensive symptom of physical and mental exhaustion and energy exhaustion, which includes emotional exhaustion, depersonalization and reduced personal accomplishment[1]. Job pressure refers to the pressure on people due to excessive workload, post change andexcessive work responsibility[2].

In China, the number of anaesthesiologists per 10000 population is only 0.4 , far lower than the number of anaesthesiologists per 10000 population in developed countries in Europe and America[3]. With the aging of the population in our country and the perioperative complications are more and more serious, the anesthesia risk is increasing day by day. At the same time, the shortage of anaesthesiologists and the uneven distribution of medical resources lead to the increaseedjob stress and burnout of anaesthesiologists, which will not only affect the physical and mental health of anaesthesiologists, but also bring hidden dangers to the safety and quality of anesthesia[4].

In Northwest China, the economy is relatively backward, the distribution of medical resources is unbalanced, and the level of medical and health services lags behind other regions[5]. Therefore, to fully mobilize the enthusiasm of medical staff, improve the level of medical services, and fully understand both the advantages and disadvantages of medical resources in this region is important forpromoting the development of medical services. So, in this study, 500 anaesthesiologists' job stress and burnout were investigated and analyzed in order to provide reference for instructing anaesthesiologists to relieve the pressure and improve the level of burnout.

\section{Methods}

The Research Ethics Committee, Xi'an Honghui Hospital Affiliated to Xi'an Jiaotong University (Chairperson: Peng Xu) approved the study on 9 April, 2020 and written informed patient consent was obtained. 
This article adheres to the applicable Enhancing the QUAlity and Transparency Of health Research (EQUATOR) guidelines.

Using random sampling method, anonymous questionnaire survey was conducted among anaesthesiologists in The Tertiary-class A Hospital in Northwest China. For sample size estimation, a pilot study of 167 cases before the survey indicated a burnout rate of $48 \%$. We assumed that a $5 \%$ error was acceptable and then set the confidence level at $95 \%$. By considering the response rate, the sample size was 308. Based on this, a total of 500 questionnaires were sent out, 408 were recovered, 336 were effective.Thus, the effective rate was $82.4 \%$.

\section{First section}

The first section of the questionnaire included 11 questions designed to capture demographic, social, and work characteristics of the anaesthesiologists: gender, age, education background, professional title, working years, family economic status, physical health status, type of hospital, proportion of anaesthesiologists in your department to operating room, ratio of anaesthesiologists to surgeons, operation volume in recent two years.

\section{Second section}

Burnout: the modified Maslach Burnout Inventory Human Service Survey (MBI-HSS)[6] was used to assess burnout. The 16-item MBI is a measure of burnout and is subdivided in three subscales: (a) Emotional exhaustion (6 items): This subscale refers to lack of emotional resources; that is, the feeling of having given everything and having nothing left to give. (b) Lack of personal accomplishment (6 items): This subscale assesses feelings of doubt about one's ability to perform tasks and lack of successful achievement in one's work with people. (c) Depersonalization (4 items): This subscale measures an unfeeling and impersonal response towards recipients of one's service, care, treatment, or instruction. The scoring method of four points was used, never so scored 0 points, rarely so scored 1 point, sometimes so scored 2 points, often so scored 3 points. In the subscale of 'emotional exhaustion', values $\geq 19$ are considered to indicate burnout; in the subscale of 'personal accomplishment', values $\leq 2.5$ are considered to indicate burnout; and in the 'depersonalization' subscale, values $\geq 17$ are considered to indicate burnout.

\section{Third section}

Job stress: the work stress of anaesthesiologists was evaluated by the Chinese Perceived Stress Scale (CPSS)[7]. There were 14 items in CPSS, which had never scored 0 , rarely scored 0.5 , sometimes scored 1 , often scored 1.5. It was conceived to assess how many life situations are appraised as stressful; that is, how unpredictable and overloaded respondents find their lives are. Higher scores indicate higher levels of job stress. At the end of the questionnaire, an open question was included for respondents to identify the main job stress factors encountered in their daily lives. The seven most frequently referred factors were identified. 


\section{Procedures}

The electronic version of the questionnaire was built on wenjuanxing platform (https://www.wjx.cn). Through WeChat publishing, which is a widely used mobile social platform that attracts a broad range of users in China. As of September 2015, WeChat had more than a billion created accounts and 650 million active users.

Throughout the nation, the coverage of WeChat has more than $90 \%$ of smartphone users[8]. It is considered as a valid questionnaire if it is collected within 3 days and the time for filling in the questionnaire is not less than 15 minutes.

\section{Statistical Analysis}

Data were analyzed using SPSS software package (Released 2017. IBM SPSS Statistics for Mac, Version 25.0. Armonk, NY: IBM Corp.). Descriptive analysis uses the number and percentage of cases to describe the general data (such as gender, age, education background, professional title, etc.), makes independent sample t-test on the scores of burnout and job stress of Anaesthesiologists of different gender, and makes one-way ANOVA on the situation of burnout and job stress of Anaesthesiologists of different age, professional title, education background, etc., among which in one-way ANOVA, the variables with $P<0.15$ were included in the multivariate analysis, the entry and removal criteria of multiple linear regression were 0.10 and 0.15 , respectively. Multiple linear regression model was used to evaluate the independent correlation between the included variables and job stress and burnout. A two-tailed $P<0.05$ was considered statistically significant.

\section{Results}

Questionnaire was distributed and collected from December 1, 2019, to February 15, 2020. Of the 32 Tertiary-class A Hospital (there are 32 Tertiary-class A Hospital in three Northwest Provinces) and 500 anaesthesiologists and anesthesia residents, 32 hospitals and 336 individuals completed the survey (response rate $100 \%$ and $82.4 \%$, respectively). The descriptive statistics are shown in Table 1.

The results of burnout analysis showed that the scores of emotion exhaustion, depersonalization and personal accomplishment were $20.23 \pm 3.515,17.98 \pm 2.310$ and $2.43 \pm 0.670$, respectively. 1 . The emotional exhaustion of anaesthesiologists with different working years and workload was different, and the difference was statistically significant $(P<0.05), 2$. The depersonalization of anaesthesiologists with different ages, titles, working years, physical conditions and workload was different, the difference was statistically significant $(P<0.05), 3$. The personal accomplishment of anaesthesiologists with different physical conditions was different, the difference was statistically significant Meaning $(P<0.05)$. Supplemental Table 1.

Analysis of job stress: anaesthesiologists with different physical health status and workload had different job stress, and the difference was statistically significant $(P<0.05)$. Supplemental Table 2 . 
Correlation analysis of influencing factors of anaesthesiologist s ' burnout: the longer the anaesthesiologist's working life, the worse the health status, the more serious the depersonalization, and the difference was statistically significant $(P<0.05)$; the better the anaesthesiologist's physical condition, the longer the working life, the higher the sense of personal accomplishment. The difference was statistically significant $(P<0.05)$. Table 2,3 and 4 .

Correlation analysis of influencing factors of job stress of anaesthesiologists: the better the physical health condition of anaesthesiologists, the less the job pressure, the difference was statistically significant $(P<0.05)$. Table 5 .

\section{Discussion}

Medical and health industry is a profession with high requirements and low sense of control, and a profession with high incidence of burnout[9]. At present, there are 76000 anaesthesiologists in China. The number of anaesthesiologists per 10000 people in China is about 0.4, compared with 3 in the United States and 2.8 in the United Kingdom. According to British and American standards, China should have 310000 anaesthesiologists. In fact, the total number of anaesthesiologists in China is less than 100000, and also less than 1 / 3 of the standard configuration, and the gap is 200000[10]. At the same time, China's surgery volume accounts for about $10 \%$ of the global surgery volume, and it is still growing at a rate of $10 \%[11]$. In recent years, the doctor-patient relationship has become increasingly tense, coupled with factors such as the income, promotion and physical condition of anaesthesiologists, which make the environment of anaesthesiologists worse. so that the job stress and burnout are increasing day by day[12].

As for emotional exhaustion, the phenomenon of emotional exhaustion with working years of 5-10 years is serious. Most anaesthesiologists who have worked for 5-10 years have accumulated professional knowledge and skills and can play an independent role at work. In hospitals at all levels, they are the main force of their department. Therefore, their emotional exhaustion is severe, which is consistent with the research results of Filippo[13]. With the increase of working years, the phenomenon of emotional exhaustion began to ease. This may be explained by the fact that, with the continuous increase of working years, their medical experience continues to be accumulated, and technical literacy is more and more suitable for the needs of the post, then the burnout will reduce. The higher the annual operation volume is, the more serious the emotional exhaustion is. The increase of workload will directly lead to the excessive fatigue of anaesthesiologists. The excessive fatigue not only affects the physical and mental health of anaesthesiologists, but also causes great potential harm to patients. In the study of Gordon[14], it was found that as many as $50 \%$ of the anaesthesiologists interviewed admitted that they had medical errors when they were tired.

With the increase of age, working years and professional titles of anaesthesiologists, their depersonalization is more and more serious. With the increasing age and working years of an anaesthesiologist, the accumulated fatigue, work pressure, dissatisfaction and sub-health will reach a 
peak, which makes the phenomenon of depersonalization more serious. The phenomenon is manifested in the negative work and indifference to colleagues. From the correlation analysis, it is found that the length of working years is positively related to the occurrence of the depersonalization, while the health status is negatively related to the occurrence of the depersonalization, the difference is statistically significant. Therefore, the relevant departments should pay attention to the physical and mental health of anaesthesiologists, which will help to delay the depersonalization and improve burnout[15].

In Northwest China, the better an anaesthesiologist's health is, the higher his accomplishment will be. In Northwest China, the economy is underdeveloped and the medical level is relatively backward. People are still in the dilemma of difficult and expensive medical treatment[16]. Novel coronavirus pneumonia (COVID-19) has been prevalent worldwide in 2020, which has caused millions of people to die. The number of deaths has reached 60 thousand, and the number of infections and deaths is rising $[17,18]$. This makes us more convinced that nothing matters except for a healthy body. Healthy body can bring more sense of personal achievement to anaesthesiologists in Northwest China. There was a positive correlation between personal accomplishment and physical health, working years, the difference was statistically significant. With the accumulation of working years, the academic level, experience and technology, salary and income of anaesthesiologists will reach a new level, and the sense of personal accomplishment will naturally increase. Coupled with a healthy body, a great sense of personal accomplishment can often be obtained, reducing the occurrence of burnout.

$88.1 \%$ of anaesthesiologists in this questionnaire had high job stress, among whom the greater the workload, the worse the physical health, the higher the job stress of anaesthesiologists, the difference was statistically significant. In the correlation analysis, job stress was negatively correlated with physical health were, the difference was statistically significant. The aforementioned shortage of anaesthesiologists in China and the increasing workloadlead to the physical and mental fatigue of medical staff and the sudden rise of pressure[19]. In addition, the sudden death rate of anaesthesiologists is increasing year by year. According to the researchers such as Shan, the proportion of sudden death of anaesthesiologists in China is the highest, reaching $26 \%[20]$. As for the reasons of excessive workload, worry about medical litigation, sleep deprivation and interpersonal relationship processing, anaesthesiologists will often be in a certain degree of physiological or psychological disease state[21], and anaesthesiologists in sick state will naturally feel the job stress increase at work. Therefore, the healthy body and mind of an anaesthesiologist are the premise and guarantee of his normal work.

In conclusion, burnout and high job pressure are common among anaesthesiologists in Northwest China. The increasing workload, unfair promotion system and long-term sub-health lead to the decline of their physical health. In terms of anaesthesiologists themselves, they should improve their psychological quality, maintain their mental health, constantly enrich and improve their professional level, and improve the communication ability between doctors and patients[22]. For the department leaders and the health administrative departments, we should first reduce the risk of occupation exposure of anaesthesiologists, then adjust the overall allocation of resources in the hospital, pay attention to the improvement and 
renewal of medical equipment, and more importantly, ensure the fairness and impartiality of the salary and promotion system, strengthen the overall input and construction of the anaesthesiology department, and strive to establish contact with the international community soon[23]. Only when we pay attention to the problems of anaesthesiologists, can we guarantee the safety and service quality of patients in the northwest region and even in the whole country, and the anaesthesiology in China can make great progress[24].

\section{Abbreviations}

EQUATOR: Enhancing the QUAlity and Transparency Of health Research

MBI-HSS: Maslach Burnout Inventory Human Service Survey

MBI: Maslach Burnout Inventory

CPSS: Chinese Perceived Stress Scale

OR: operating room

\section{Declarations}

\section{Acknowledgments}

The authors thank the anaesthesiologist who participated in the study and for their helpfulness and support.

\section{Authors' contributions}

JMY, ZQ and BHD designed and conducted of the study. GY, XLF and MH collected, analyzed and interpreted the data. All authors have participated in writing the manuscript. All authors read and approved the final manuscript.

\section{Funding}

This study was self-financed.

\section{Availability of data and materials}

The data used to support the findings of this study are available from the corresponding author upon request.

\section{Ethics approval and consent to participate}

The Research was approved by the Ethics Committee of Xi'an Honghui Hospital Affiliated to Xi'an Jiaotong University (Chairperson: Peng Xu) and registered at http://www.chictr.org.cn (27/3/2021, 
ChiCTR2000031316). This article adheres to the applicable Enhancing the QUAlity and Transparency Of health Research(EQUATOR) guidelines. Written informed patient consent was obtained.

\section{Consent for publication}

Not applicable.

\section{Competing interests}

The authors have no conflicts of interest to declare.

\section{References}

1. Durham M, Bush P, Ball A: Evidence of burnout in health-system pharmacists. American journal of health-system pharmacy: AJHP : official journal of the American Society of Health-System Pharmacists 2018, 75:S93-S100.

2. Chirico F: Job stress models for predicting burnout syndrome: a review. Annali dell'Istituto superiore di sanita 2016, 52(3):443-456.

3. Li Q, Han T, Zhang Y, Zhang Q, Kong X, Yang Y, Feng Z: A nationwide survey on neonatal medical resources in mainland China: current status and future challenges. BMC pediatrics 2019, 19(1):436.

4. Lapa T, Madeira F, Viana J, Pinto-Gouveia J: Burnout syndrome and wellbeing in anesthesiologists: the importance of emotion regulation strategies. Minerva anestesiologica 2017, 83(2):191-199.

5. Cai H, Wang H, Guo T, Bao G: Application of Telemedicine in Gansu Province of China. PloS one 2016, 11(6):e0158026.

6. Maslach Burnout Inventory [https://

7. Lu W, Bian Q, Wang W, Wu X, Wang Z, Zhao M: Chinese version of the Perceived Stress Scale-10: A psychometric study in Chinese university students. PloS one 2017, 12(12):e0189543.

8. Montag C, Becker B, Gan C: The Multipurpose Application WeChat: A Review on Recent Research. Frontiers in psychology 2018, 9:2247.

9. Lederer W, Paal P, von Langen D, Sanwald A, Traweger C, Kinzl J: Consolidation of working hours and work-life balance in anaesthesiologists - A cross-sectional national survey. PloS one 2018, 13(10):e0206050.

10. Li Z, Yang J, Wu Y, Pan Z, He X, Li B, Zhang L: Challenges for the surgical capacity building of township hospitals among the Central China: a retrospective study. International journal for equity in health 2018, 17(1):55.

11. Lu J, Wang W, Cheng W, Chen L, Huang J, Ethridge C, Huang J: Current Status of Cardiovascular Anesthesia in China. Anesthesia and analgesia 2017, 125(6):1855-1862.

12. De Hert S: Burnout Among Anesthesiologists: It]s Time for Action! Journal of cardiothoracic and vascular anesthesia 2018, 32(6):2467-2468. 
13. Sanfilippo F, Noto A, Foresta G, Santonocito C, Palumbo G, Arcadipane A, Maybauer D, Maybauer M: Incidence and Factors Associated with Burnout in Anesthesiology: A Systematic Review. BioMed research international 2017, 2017:8648925.

14. Gordon P, Llewellyn R, James M: Drug administration errors by South African anaesthetists-a survey. South African medical journal = Suid-Afrikaanse tydskrif vir geneeskunde 2006, 96(7):630632.

15. Katz J: The impaired and/or disabled anesthesiologist. Current opinion in anaesthesiology 2017, 30(2):217-222.

16. Zeng C, Lane N, Englund M, Xie D, Chen H, Zhang Y, Wang H, Lei G: In-hospital mortality after hip arthroplasty in China: analysis of a large national database. The bone \& joint journal 2019(10):1209-1217.

17. Velavan T, Meyer C: The COVID-19 epidemic. Tropical medicine \& international health: TM \& IH2020, 25(3):278-280.

18. Rothan HA, Byrareddy SN: The epidemiology and pathogenesis of coronavirus disease (COVID-19) outbreak. J Autoimmun 2020, 109:102433.

19. Saadat $\mathrm{H}, \mathrm{Kain} \mathrm{Z}$ : Wellness interventions for anesthesiologists. Current opinion in anaesthesiology 2018, 31(3):375-381.

20. Zhang H, Li F, Lei H, Xu S: Rising sudden death among anaesthesiologists in China. British journal of anaesthesia 2017, 119(1):167-169.

21. De Oliveira G: Biological evidence of the impact of burnout on the health of anesthesiologists. Journal of clinical anesthesia 2017, 41:62.

22. Scaioli G, Schafer WLA, Boerma WGW, Spreeuwenberg P, van den Berg M, Schellevis FG, Groenewegen PP: Patients' perception of communication at the interface between primary and secondary care: a cross-sectional survey in 34 countries. BMC Health Serv Res 2019, 19(1):1018.

23. Ravi S: Strengthening Health Systems Through International Blood Product Sharing Agreements. Health security 2017, 15(1):110-117.

24. Zhao J, Yu W, Tong C, Xie Z, Sun J, Zhou S, Liu H, Meng L: Adopting the American anesthesia oral examination in China: value and roadblocks. Journal of clinical anesthesia 2016, 30:42-45.

\section{Tables}


Table 1

Descriptive Statistics of the Survey $(n=336)$

\begin{tabular}{|c|c|c|c|}
\hline Project & Category & Number & Proportion(\%) \\
\hline \multicolumn{4}{|l|}{ Gender } \\
\hline & Male & 157 & 46.73 \\
\hline & Female & 179 & 53.27 \\
\hline \multicolumn{4}{|l|}{ Age(y) } \\
\hline & $<25$ & 6 & 1.79 \\
\hline & $25-30$ & 73 & 21.73 \\
\hline & $31-35$ & 79 & 23.51 \\
\hline & $36-45$ & 114 & 33.93 \\
\hline & $>45$ & 64 & 19.05 \\
\hline \multicolumn{4}{|c|}{ Education } \\
\hline & Junior college and below & 22 & 6.55 \\
\hline & Undergraduate & 262 & 77.98 \\
\hline & Master & 49 & 14.58 \\
\hline & Doctor & 3 & 0.89 \\
\hline \multicolumn{4}{|l|}{ Title } \\
\hline & Intern & 3 & 0.89 \\
\hline & Resident physician & 115 & 34.23 \\
\hline & Attending doctor & 131 & 38.99 \\
\hline & Deputy chief physician & 77 & 22.92 \\
\hline & Chief physician & 10 & 2.98 \\
\hline \multicolumn{4}{|c|}{ Working life(y) } \\
\hline & $<5$ & 74 & 22.03 \\
\hline & $5-10$ & 79 & 23.51 \\
\hline & $11-20$ & 100 & 29.76 \\
\hline & $21-30$ & 66 & 19.64 \\
\hline
\end{tabular}

Data are presented as frequency and percentage.

Abbreviation: OR, operating room. 


\begin{tabular}{|c|c|c|c|}
\hline Project & Category & Number & Proportion(\%) \\
\hline & $>30$ & 17 & 5.06 \\
\hline \multicolumn{4}{|l|}{ Family financial situation } \\
\hline & Rich & 16 & 4.76 \\
\hline & General & 227 & 67.56 \\
\hline & Income $=$ expenditure & 83 & 24.70 \\
\hline & Poor & 10 & 2.98 \\
\hline \multicolumn{4}{|l|}{ Physical condition } \\
\hline & Healthy & 52 & 15.48 \\
\hline & Sub-health & 251 & 74.70 \\
\hline & Suffer from disease & 33 & 9.82 \\
\hline \multicolumn{4}{|l|}{ Type of hospital } \\
\hline & Public teaching hospital & 57 & 16.96 \\
\hline & Public specialized hospital & 61 & 18.15 \\
\hline & Public general hospital & 218 & 64.88 \\
\hline \multicolumn{4}{|l|}{ Anaesthesiologist / OR } \\
\hline & $>3: 1$ & 14 & 4.17 \\
\hline & $2.5-3: 1$ & 28 & 8.33 \\
\hline & $2-2.5: 1$ & 53 & 15.77 \\
\hline & $1-2: 1$ & 202 & 60.12 \\
\hline & $<1$ & 39 & 11.61 \\
\hline \multicolumn{4}{|l|}{ Anaesthesiologist / surgeon } \\
\hline & $<0.1$ & 53 & 15.77 \\
\hline & $0.1-0.2$ & 161 & 47.92 \\
\hline & $0.21-0.3$ & 73 & 21.73 \\
\hline & $>0.3$ & 49 & 14.58 \\
\hline Operation volume in recent two years & $<3000$ & 100 & 29.76 \\
\hline
\end{tabular}

Data are presented as frequency and percentage.

Abbreviation: OR, operating room. 


\begin{tabular}{|llll|}
\hline Project & Category & Number & Proportion(\%) \\
\hline & $3000-6000$ & 80 & 23.81 \\
\hline $6001-12000$ & 86 & 24.70 \\
& $12001-20000$ & 25 & 7.44 \\
& $>20000$ & 48 & 14.29 \\
\hline $\begin{array}{l}\text { Data are presented as frequency and percentage. } \\
\text { Abbreviation: OR, operating room. }\end{array}$ & & \\
\hline
\end{tabular}

Table 2

Results of Multiple Linear Regression of Emotional Exhaustion

\begin{tabular}{|lllll|}
\hline Project & $\mathbf{b}$ & Std b & $\mathbf{t}$ & $\boldsymbol{P}$ Value \\
\hline Constant & 18.548 & & 14.346 & $<0.001$ \\
\hline Working life & -0.157 & -0.052 & -0.930 & 0.353 \\
\hline Anaesthesiologist / OR & 0.255 & 0.068 & 1.246 & 0.213 \\
\hline Anaesthesiologist / surgeon & -0.392 & -0.102 & -1.869 & 0.062 \\
\hline Operation volume in recent two years & 0.249 & 0.097 & 1.718 & 0.087 \\
\hline \begin{tabular}{l} 
The entry and removal criteria of multiple linear regression were 0.10 and 0.15, respectively. For this \\
model, $\mathrm{R}^{2}=0.044$, Adjusted $\mathrm{R}^{2}=0.030, \mathrm{~F}=3.052, \mathrm{P}=0.010$. \\
\hline
\end{tabular} & & & \\
\hline Abbreviation: OR, operating room. & & & \\
\hline
\end{tabular}


Table 3

Results of Multiple Linear Regression of Depersonalization

\begin{tabular}{|c|c|c|c|c|}
\hline Project & b & Std b & $\mathrm{t}$ & $P$ Value \\
\hline Constant & 13.967 & & 18.034 & $<0.001$ \\
\hline Age & 0.008 & 0.107 & 0.842 & 0.401 \\
\hline Education & -0.035 & -0.007 & -0.135 & 0.893 \\
\hline Title & -0.124 & -0.046 & -0.592 & 0.554 \\
\hline Working life & 0.788 & 0.400 & 3.201 & 0.002 \\
\hline Physical condition & -0.608 & -0.132 & -2.693 & 0.007 \\
\hline Operation volume in recent two years & 0.164 & 0.097 & 1.847 & 0.066 \\
\hline \multicolumn{5}{|c|}{$\begin{array}{l}\text { The entry and removal criteria of multiple linear regression were } 0.10 \text { and } 0.15 \text {, respectively. For this } \\
\text { model, } R^{2}=0.240 \text {, Adjusted } R^{2}=0.227, F=17.354, P<0.010 \text {. }\end{array}$} \\
\hline \multicolumn{5}{|c|}{$P$ value of $<0.05$ was regarded as statistically significant. } \\
\hline
\end{tabular}

Table 4

Results of Multiple Linear Regression of Personal Accomplishment

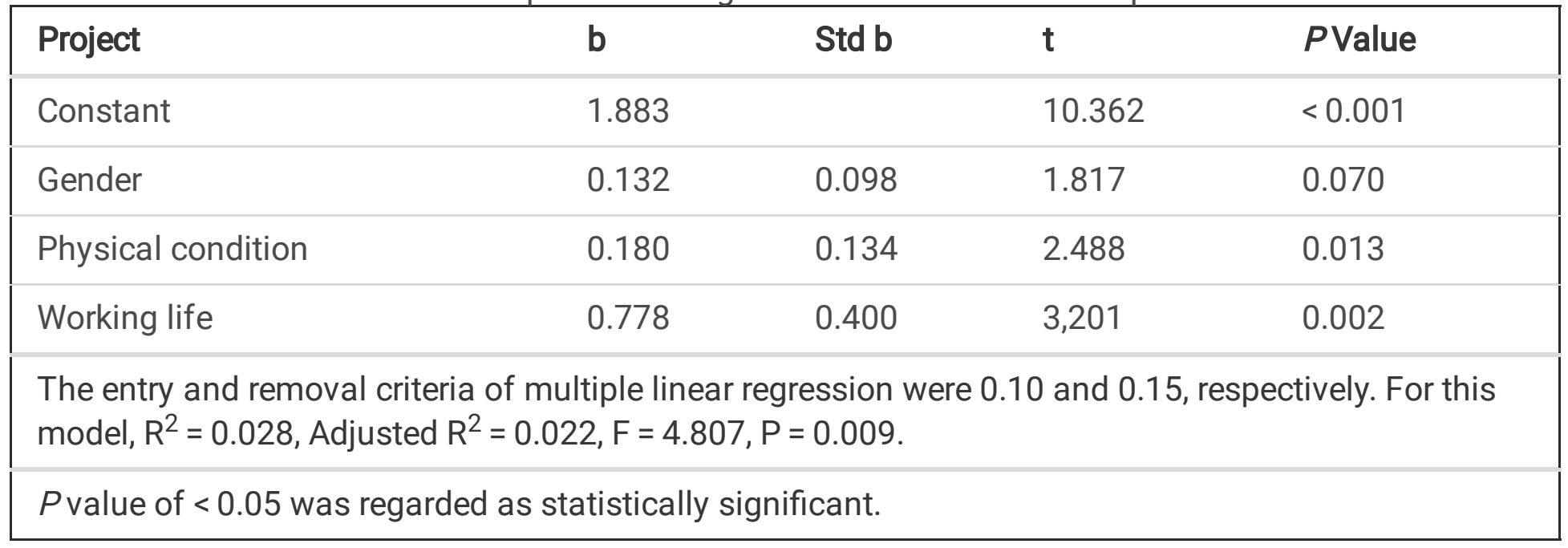


Table 5

Results of Multiple Linear Regression of Personal Accomplishment Job Stress

\begin{tabular}{|llccc|}
\hline Project & $\mathbf{b}$ & $\mathbf{S t d} \mathbf{b}$ & $\mathbf{t}$ & $\boldsymbol{P}$ Value \\
\hline Constant & 5.008 & & 7.943 & $<0.001$ \\
\hline Age & 0.280 & 0.171 & 1.294 & 0.196 \\
\hline Working life & -0.150 & -0.099 & -0.742 & 0.459 \\
\hline Physical condition & -0.477 & -0.135 & -2.471 & 0.014 \\
\hline Anaesthesiologist / OR & 0.180 & 0.095 & 1.749 & 0.081 \\
\hline Operation volume in recent two years & 0.133 & 0.102 & 1.843 & 0.066 \\
\hline $\begin{array}{l}\text { The entry and removal criteria of multiple linear regression were } 0.10 \text { and } 0.15, \text { respectively. For this } \\
\text { model, } \mathrm{R}^{2}=0.049 \text {, Adjusted } \mathrm{R}^{2}=0.034, \mathrm{~F}=3.379, \mathrm{P}=0.005 . \\
\end{array}$ & & & \\
\hline Abbreviation: OR, operating room. & & & \\
\hline
\end{tabular}

\section{Supplementary Files}

This is a list of supplementary files associated with this preprint. Click to download.

- SupplementalTable1.docx

- SupplementalTable2.docx 